\title{
Nebivolol effect on doxorubicin-induced cardiotoxicity in breast cancer
}

\author{
Flavia Cochera* \\ Daniel Dinca* \\ Diana Aurora Bordejevic \\ Ioana Mihaela Citu \\ Adelina Marioara Mavrea \\ Minodora Andor \\ Mihai Trofenciuc \\ Mirela Cleopatra Tomescu \\ Cardiology Department, "Victor \\ Babes" University of Medicine and \\ Pharmacy, Timisoara, Romania \\ *These authors contributed equally to \\ this work
}

This article was published in the following Dove Press journal: Cancer Management and Research

Purpose: The aim of this study was to assess whether nebivolol treatment could have beneficial effects in the prevention of anthracyclines-induced cardiotoxicity.

Patients and methods: Our prospective study included 60 women, mean age 52.6 \pm 13 years, with HER2 negative breast cancer, scheduled to undergo treatment with doxorubicin. The patients were randomly divided into two groups: the treatment group $(n=30)$ which received nebivolol 5 mg once daily for the duration of chemotherapy and the control group $(n=30)$ without treatment with nebivolol. Cytostatic treatment was performed with doxorubicin $70 \mathrm{mg} / \mathrm{m}^{2}$ administered intravenously every 21 days for six cycles. The average cumulative dose of doxorubicin was $520 \pm 8 \mathrm{mg} / \mathrm{m}^{2}$. Echocardiography was performed immediately before and after six cycles of doxorubicin therapy.

Results: We found no significant differences between the two groups regarding baseline clinical and echocardiographic parameters. The two groups reached a similar cumulative dose of doxorubicin. No patient died during the study. None of the patients withdrew from chemotherapy. After six cycles of doxorubicin therapy, the left ventricular (LV) ejection fraction, shortening fraction, and LV diameters changed, but not significantly. Tissue Doppler imaging (TDI) detected in the control group a significant decrease of myocardial velocities, indicating a LV diastolic dysfunction. In the same group, speckle tracking imaging (STI) revealed a statistically significant alteration of the ventricular deformation, which means a decrease in LV systolic function. In the nebivolol treatment group, no significant alterations in the LV systolic and diastolic function were observed.

Conclusion: The results of this study show the benefit of new echocardiographic imaging methods such as TDI and STI in the screening of early cardiac dysfunction induced by cytostatic treatment. Nebivolol treatment prevented the occurrence of anthracyclines-induced cardiomyopathy in the short term. In order to confirm these preliminary results, larger studies with a longer follow-up period are required.

Keywords: breast cancer, doxorubicin, nebivolol, echocardiography, cardiotoxicity, cardioprotection

\section{Introduction}

Correspondence: Diana Aurora Bordejevic

Cardiology Department, "Victor Babes"

University of Medicine and Pharmacy, 2nd

Eftimie Murgu Square, Timisoara 30004I,

Romania

$\mathrm{Tel}+40734600550$

Fax +40256220636

Email aurora.bordejevic@umft.ro

Breast cancer is an important public health problem all around the world, with a death rate of nearly 1 in $33 .{ }^{1}$ Anthracyclines are potent pharmacological agents with a broad widely used antineoplastic spectrum in the treatment of breast cancer..$^{2-4}$

Doxorubicin is an anthracycline widely used in various cytostatic treatment regimens, but has limited applicability, being cardiotoxic. This cardiotoxicity increases patient morbidity and mortality. The mechanisms of cardiotoxicity induced by 
anthracyclines include the formation of oxygen free radicals, damage directly to the DNA, apoptosis, activation of immunological reactions in the myocardium, changes in calcium ions transport, histamine release, and activation of coagulation with the formation of thrombus in coronary arteries. ${ }^{5}$ Doxorubicin-induced cardiotoxicity may be augmented by increased cumulative dose, association with other cytotoxic drugs, and patients' advanced age. Although cardiotoxicity is a recognized side effect of anthracyclines, early detection of subclinical changes in contractility is very difficult to assess. Classically, depressed myocardial contractility is based on the estimation of left ventricular ejection fraction (LVEF) and shortening fraction (SF). However, those are affected in the advanced stages of cardiotoxicity. Echocardiography $\mathrm{M}$ mode allows the assessment of myocardial deformation but has limitations in terms of determining the number of affected segments, and it allows only radial measurements. Therefore, it is considered that evaluation with standard echocardiography M mode overestimates the left ventricular (LV) systolic performance. ${ }^{6}$ In contrast, strain rate imaging allows the measurement of local myocardial deformations with a very high accuracy. A number of recent studies have demonstrated the usefulness of strain rate imaging in the early detection of anthracycline-induced cardiotoxicity, before impairment of the LVEF. ${ }^{7}$

Echocardiographic markers, such as changes in LV myocardial velocities assessed by tissue Doppler imaging (TDI), and LV deformity as assessed by speckle tracking imaging (STI), are markers of LV subclinical dysfunction, and thus allow for early detection and early therapy of cardiac toxicity induced by anthracyclines by cardioprotective medication.

Nebivolol is a $\beta 1$-selective adrenergic receptor blocker with antioxidant, antiapoptotic, and vasodilator properties mediated by nitric oxide release. It is used in the treatment of arterial hypertension and cardiac insufficiency and it could have beneficial effects in preventing cardiac toxicity induced by anthracyclines. ${ }^{8,9}$

The hypothesis on which this study was based was that nebivolol could exert a preventive effect on doxorubicininduced cardiotoxicity in breast cancer patients.

\section{Materials and methods}

This prospective study included 60 patients with HER2 negative breast cancer (median age 52.6 \pm 13 years) who were scheduled to receive doxorubicin therapy. Cardiology evaluation was performed at the Cardiology Clinic of the Timisoara Municipal Hospital. The inclusion criteria were 1) age $>18$ years; 2) patient's signed agreement to participate in the study; 3) HER2 negative breast cancer diagnosis, previously untreated, with an indication of chemotherapy according to standardized international protocols; 4) LVEF $\geq 50 \%$. The exclusion criteria included 1) pregnancy and breastfeeding; 2) previous radiotherapy or prior therapy with cytostatics; 3) the use of cardioprotective drugs - such as angiotensin converting enzyme inhibitors, statins, calcium channel blockers, angiotensin receptor blockers, anti-aldosterone, and other adrenergic beta-blockers; 4) presence of a diagnosed cardiopathy in the initial clinical and echocardiographic evaluation; 5) history of chronic diseases such as diabetes mellitus, hypertension, chronic kidney disease, chronic liver disease; 6) contraindications for the treatment of beta-adrenergic blocker; and 7) doxorubicin intolerance.

All patients provided written informed consent for participation in the study. The study was approved by the Ethics Committee of the "Victor Babes" University of Medicine and Pharmacy, Timisoara.

Cytostatic treatment was provided with doxorubicin 70 $\mathrm{mg} / \mathrm{m}^{2}$ administered intravenously in monotherapy at 21-day intervals. Six cycles of cytostatic therapy were performed. The cumulative mean dose of doxorubicin was $520 \pm 8 \mathrm{mg} / \mathrm{m}^{2}$.

Patients were randomly divided into two groups: the study group $(\mathrm{n}=30)$ which received nebivolol $5 \mathrm{mg} /$ day in a single daily dose, for the duration of the chemotherapy process, and the control group $(n=30)$ without nebivolol treatment.

Echocardiography was performed conventionally with imaging for the determination of myocardial velocities by TDI and STI. Echocardiographic examinations were carried out prior to chemotherapy and then within 24 hours after the sixth chemotherapy cycle (on average $110 \pm 12$ days after the initial echocardiographic evaluation). Cardiotoxicity is typically defined as a decrease in LVEF by $\geq 10 \%$ from prechemotherapy values or to a value $<55 \%$ without evident symptoms or clinical signs of heart failure. ${ }^{10}$ However, a series of echocardiographic parameters such as myocardial, strain, and strain rates are more sensitive than LVEF, allowing for the identification of ventricular dysfunction at an early stage. Vivid S5 (GE Healthcare Bio-Sciences Corp, Piscataway, NJ, USA) was used with a medium frequency transducer (3-8 $\mathrm{MHz}$ ). Diameters of cardiac cavities and ejection fractions were calculated according to the American Society of Echocardiography guidelines. ${ }^{10}$ Doppler examination of mitral valves was performed in the four-chamber apical incidence with the volume specimen placed at the mitral valve tip. The following parameters were determined: the maximal protodiastolic velocity of the transmitral flow (peak E), the 
maximal telediastolic velocity (peak A), the E/A ratio, and the isovolumic relaxation time (IVRT).

Tissue Doppler images were recorded and stored in the form of video content. Their analysis was performed off-line using the EchoPAC system version 11.0.1 (GE Healthcare Bio-Sciences Corp). Analysis by tissue Doppler of mitral annular velocity was carried out within the apical fourchamber incidence.

A sample volume of $5 \mathrm{~mL}$ was placed at the septal and lateral ends of the mitral ring. Video sequences of five consecutive cardiac cycles were recorded using a transducer with frequencies of 2-4 MHz. M-mode measurements were performed on the parasternal long axis, and the thickness of the interventricular septum, the posterior wall, and the left ventricle diameters were used to calculate SF. LVEF was calculated at four and two apical incidences by using Simpson method. The diastolic function of the left ventricle was assessed using the transmitral Doppler flow, calculating the $\mathrm{E} / \mathrm{A}$ ratio. The pulsed tissue Doppler flow was positioned parallel to the direction of movement of the mitral ring. In the four-, three-, and two-chamber apical incidence, the twodimensional (2D) mode, the ventricular myocardial function of the septal and lateral segments was evaluated by TDI, taking care that the angle between the Doppler beam and the tissue was $<30^{\circ}$. The maximum velocity in the protodiastolic (E') was measured in the basal myocardial segments, in the apical incidence of four chambers, at the level of the mitral ring, in the septal and lateral segments. The E/E' ratio was calculated, which we considered a parameter of ventricular filling pressure.

Two-dimensional speckle tracking imaging (2D STI) has been assessed for global myocardial deformation using a frequency of 70-80 frames/s and also by adjusting the device to achieve a depth and optimal sectorial width. The frame was selected to allow the best definition of the endocardium, and the endocardium edge was automatically drawn and corrected manually. After defining the region of interest in the long or circumferential axis, the software automatically divided the ventricle into six equal segments. Speckle tracking of these six segments was analyzed by using three apical incidences, four, three, and two chambers.

The time intervals had as references, the opening and closing of the aortic valves. The global longitudinal strain and its rate were calculated as the average of the 18 analyzed segments. Global radial and global circumferential strain were calculated from the mean maximum systolic values of the 18 left ventricle segments in the short left parasternal axis incidence, at the apex, middle segment, and basal segment of the left ventricle. The circumferential and radial global strain rates were also calculated.

All TDI and STI measurements were calculated for three consecutive cardiac cycles, the arithmetic mean being achieved. Echocardiographic examinations were performed by the same investigator.

Reproducibility and repeatability of determinations have been checked for all echocardiographic parameters. The testing retesting variability was calculated by the formula 2 standard deviations $/ \sqrt{ } 2$ and was expressed as a percentage difference from the mean, resulting in the coefficient of variability $(3.5 \pm 1.5 \%) .{ }^{11}$

\section{Statistics}

Statistical analysis was performed using the MedCalc statistical software version 12.7.7 (MedCalc Software, Ostend, Belgium). The minimum number of patients for each group was calculated as 27 . This calculation was based on the reproducibility of the TDI and STI determinations so that differences of $>5 \%$ between consecutive measurements were statistically significant. Continued data were expressed as mean \pm standard deviation and significant as a percentage. Differences between groups and within the same group before and after the sixth doxorubicin treatment cycle were compared by the paired $t$-test. Statistical values of $P<0.05$ were considered significant.

\section{Results}

The clinical characteristics of the patients are presented in Table 1. All patients were women. We found no significant differences between groups for the following parameters: age, body mass index, systolic and diastolic blood pressure values, heart rate, $\mathrm{LVEF}, \mathrm{SF}$, and $\mathrm{E} / \mathrm{A}$ ratio. The cumulative dose of doxorubicin was similar between the two groups. None of the patients died or discontinued chemotherapy during the study.

\section{Echocardiography}

LVEF, SF, LV diameters remained normal in all patients after chemotherapy and did not change significantly from baseline, except for mitral annular plane systolic excursion, that decreased significantly in the control group $(P=0.03)$. Also, diastolic parameters did not significantly change after doxorubicin treatment except for IVRT in group I, as shown in Table 2.

TDI and STI parameters were comparable between the two groups before chemotherapy. After six cycles of doxorubicin chemotherapy, we observed significant changes of these parameters in $27(45 \%)$ patients, $7(23 \%)$ among the 
Table I General clinical characteristics of the patients with breast cancer

\begin{tabular}{|c|c|c|c|}
\hline & $\begin{array}{l}\text { Group with } \\
\text { nebivolol }(n=30)\end{array}$ & $\begin{array}{l}\text { Control group } \\
(n=30)\end{array}$ & $P$-value \\
\hline Age (years) & $53 \pm 13$ & $52 \pm 11$ & 0.74 \\
\hline BMI $\left(\mathrm{kg} / \mathrm{m}^{2}\right)$ & $22.6 \pm 2.8$ & $23.3 \pm 3.2$ & 0.37 \\
\hline Systolic blood pressure $(\mathrm{mmHg})$ & $133 \pm 14$ & $132 \pm 9$ & 0.74 \\
\hline Diastolic blood pressure $(\mathrm{mm} \mathrm{Hg})$ & $78 \pm 6$ & $79 \pm 6$ & 0.52 \\
\hline Heart rate (beats/min) & $77 \pm 7$ & $79 \pm 10$ & 0.37 \\
\hline \multicolumn{4}{|l|}{ Cardiovascular risk factors } \\
\hline$-\mathrm{BP} \geq 140 / 90 \mathrm{mmHg}$ & 0 & 0 & 1 \\
\hline - Total cholesterol $>200 \mathrm{mg} / \mathrm{dL}$ & $4(13)$ & $3(10)$ & 0.96 \\
\hline - Diabetes mellitus & 0 & 0 & 1 \\
\hline - Smoking & $2(6)$ & $3(10)$ & 0.92 \\
\hline Cumulative dose of doxorubicin $\left(\mathrm{mg} / \mathrm{m}^{2}\right)$ & $521 \pm 6$ & $519 \pm 9$ & 0.31 \\
\hline
\end{tabular}

Note: Data are expressed as mean \pm SD or number (percentage).

Abbreviations: BMI, body mass index; BP, blood pressure.

Table 2 Conventional echocardiographic parameters

\begin{tabular}{|c|c|c|c|c|c|}
\hline & \multirow[t]{2}{*}{$\begin{array}{l}\text { Group with } \\
\text { nebivolol }(n=30)\end{array}$} & \multirow[t]{2}{*}{$\begin{array}{l}\text { Control group } \\
(n=30)\end{array}$} & \multirow[t]{2}{*}{$\begin{array}{l}P \text {-value between } \\
\text { groups I and II }\end{array}$} & \multicolumn{2}{|c|}{$\begin{array}{l}P \text {-value between baseline and final } \\
\text { measurements }\end{array}$} \\
\hline & & & & Group I & Group II \\
\hline \multicolumn{6}{|l|}{ LVED } \\
\hline Initial & $45.1 \pm 4.2$ & $44.8 \pm 4.2$ & 0.78 & 0.24 & 0.19 \\
\hline Final & $46.2 \pm 2.9$ & $46.1 \pm 3.5$ & 0.90 & & \\
\hline \multicolumn{6}{|l|}{ LVES } \\
\hline Initial & $27.8 \pm 3.1$ & $27.5 \pm 2.8$ & 0.69 & 0.63 & 0.18 \\
\hline Final & $28.1 \pm 1.6$ & $28.3 \pm 1.7$ & 0.64 & & \\
\hline \multicolumn{6}{|l|}{ LVEF } \\
\hline Initial & $62 \pm 4$ & $61 \pm 2$ & 0.22 & 0.27 & 0.13 \\
\hline Final & $6 I \pm 3$ & $60 \pm 3$ & 0.20 & & \\
\hline \multicolumn{6}{|l|}{ SF } \\
\hline Initial & $40 \pm 4$ & $4 I \pm 2$ & 0.22 & 0.22 & 0.13 \\
\hline Final & $39 \pm 2$ & $40 \pm 3$ & 0.13 & & \\
\hline \multicolumn{6}{|l|}{$E / A$} \\
\hline Initial & $1.3 \pm 0.5$ & $1.2 \pm 0.4$ & 0.39 & 0.16 & 0.13 \\
\hline Final & $1.1 \pm 0.6$ & $1.0 \pm 0.5$ & 0.48 & & \\
\hline \multicolumn{6}{|l|}{ IVRT } \\
\hline Initial & $65.1 \pm 1.8$ & $65.3 \pm 2.1$ & 0.68 & $0.01 *$ & 0.33 \\
\hline Final & $63.9 \pm 1.9$ & $64.8 \pm 1.9$ & 0.07 & & \\
\hline \multicolumn{6}{|l|}{ MAPSE } \\
\hline Initial & $14.7 \pm 2.5$ & $\mid 4.7 \pm 2.1$ & I & 0.18 & $0.03^{*}$ \\
\hline Final & $13.8 \pm 2.7$ & $\mid 3.7 \pm 1.3$ & 0.85 & & \\
\hline
\end{tabular}

Notes: Data are expressed as mean \pm SD. ${ }^{*} P<0.05$ between baseline and end, within the same group.

Abbreviations: LVED, end diastolic diameter of the left ventricle; LVES, end systolic diameter of the left ventricle; LVEF, ejection fraction of the left ventricle; SF, shortening fraction; E, left ventricular protodiastolic filling wave; A, left ventricular end diastolic filling wave; IVRT, isovolumic relaxation time; MAPSE, mitral annular plane systolic excursion.

nebivolol-treated group and $20(66 \%)$ in the control group $(P=0.001)$, as shown in Figure 1.

In the control group, a significant reduction in LV diastolic function was assessed by changes in E' lateral ( $P=0.01)$, E' septal $(P=0.02)$, and $\mathrm{E} / \mathrm{E}$ ' velocities ratio $(P=0.03)$ (Table 3).
In the control group, we also noticed a statistically significant decrease in LV systolic function, as measured by its longitudinal strain $(P=0.04)$ (Figure 2), its radial strain $(P=0.03)$ (Figure 3 ), as well as by the corresponding strain rates $(P=0.02)$ (Table 3$)$. There was no significant change in the LV circumferential strain and strain rate. 


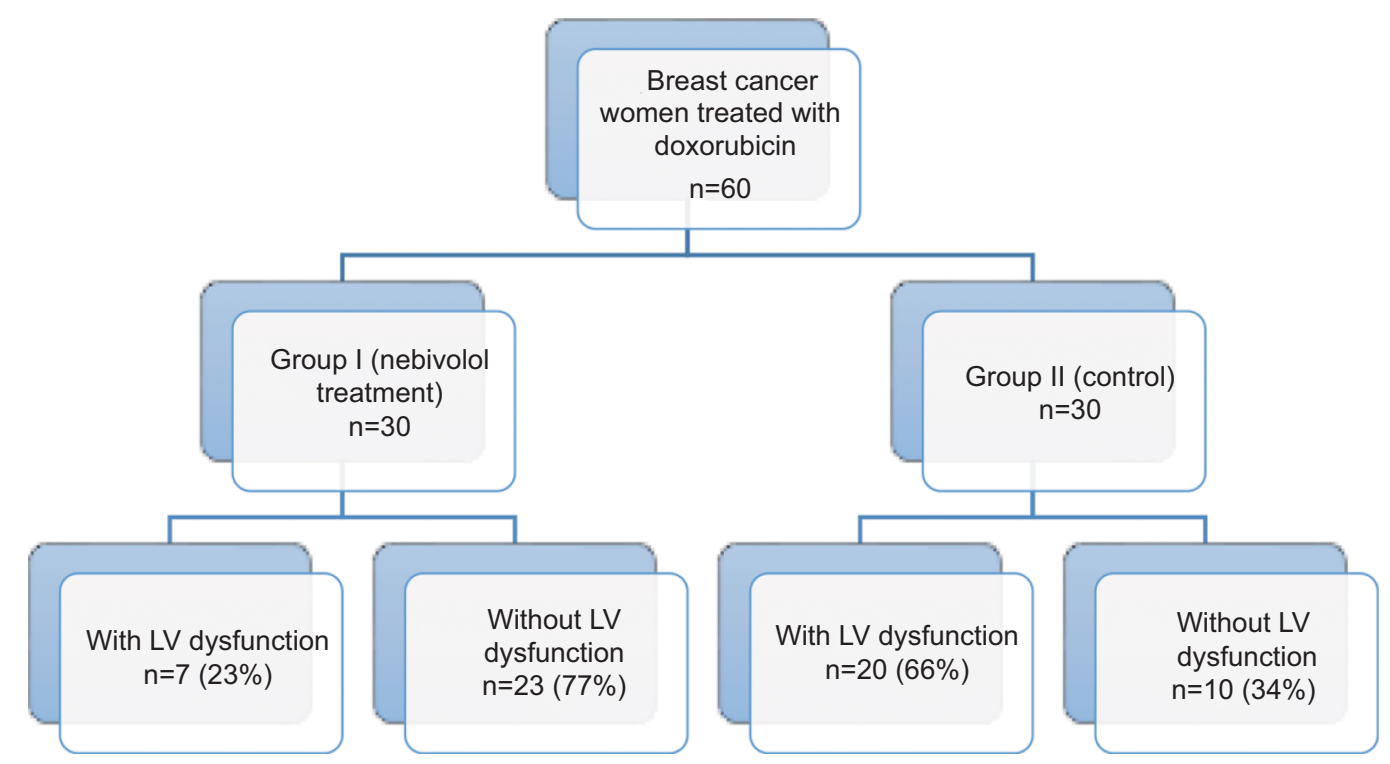

Figure I Changes in tissue Doppler and speckle tracking imaging parameters assessing subclinical LV dysfunction after doxorubicin therapy. Abbreviation: LV, left ventricular.

Changes in systolic and diastolic LV function also occurred in the nebivolol-treated group but were not statistically significant, which supports the cardioprotective role of nebivolol (Table 3).

These data demonstrate a reduction in the longitudinal and radial myocardial contractile function of the LV myocardium following doxorubicin therapy, representing subclinical signs of cardiotoxicity. Figures 4-6 show obvious changes in LV systolic deformity in a control group patient, after six cycles of doxorubicin therapy. These changes were subclinical; they did not induce symptoms.

\section{Discussion}

Anthracyclines are antineoplastic agents with high efficacy in the treatment of many hematologic and solid organ cancers. The clinical impact of dose-induced anthracycline cardiomyopathy is growing with increasing cancer survivorship. Anthracycline cardiotoxicity is known as type 1 cardiotoxicity, characterized by cardiomyocyte death and irreversible cardiac injury. ${ }^{10}$ Type 2 cardiotoxicity, induced by trastuzumab, is characterized by cardiomyocyte dysfunction and therefore is reversible. ${ }^{11}$

Doxorubicin is an anthracycline agent associated with unpredictable cardiotoxicity. The mechanisms of doxorubicin-induced cardiotoxicity are a multifactorial result of different processes such as oxidative stress, the release of vasoactive amines, inhibition of nucleic acid and protein synthesis, activation of the ubiquitin-proteasome system, abnormalities in $\mathrm{Ca}^{2+}$ management, impaired cardiac repair due to inhibition of bone marrow and cardiac progenitor cells. ${ }^{12,13}$ Vulnerability to doxorubicin cardiotoxicity is largely patient dependent, suggesting genetic predisposition, and some studies found that this condition was associated with dysregulation of genes implicated both in inflammation and autoimmune disorders. ${ }^{14}$

There is new and growing evidence highlighting a cardioprotective effect of third generation beta-blockers in the prevention of anthracycline-induced cardiomyopathy. ${ }^{15}$ Third generation beta-blockers, such as carvedilol and nebivolol, have additional vasodilation properties. Carvedilol is a $\beta 1$-nonselective adrenergic receptor antagonist that induces vasodilatation through the $\alpha 1$-receptor blockade, has antioxidant properties and the ability to chelate iron. ${ }^{16,36}$ Nebivolol is a $\beta 1$-selective adrenergic receptor antagonist that induces endothelium-dependent vasodilatation by stimulating nitric oxide bioactivity. ${ }^{8}$ Both carvedilol ${ }^{17}$ and nebivolol ${ }^{18}$ used at the initiation of anthracycline use were proven to have beneficial effects on the preservation of LVEF. Not all beta-blockers are efficient in preventing cardiomyopathy in patients undergoing chemotherapy. The first generation, non- $\beta 1$-selective beta-blockers, such as propranolol, may enhance anthracycline cardiotoxicity, ${ }^{19}$ while second generation, $\beta 1$-selective beta-blockers, such as metoprolol, have a neutral effect in this regard. ${ }^{20}$

This study evaluated the protective role of nebivolol against the occurrence of anthracycline-induced cardiotoxicity in breast cancer patients. After a 3-month interval, echocardiography may detect early signs of cardiopathy 
Table 3 Tissue Doppler and speckle tracking echocardiographic imaging parameters

\begin{tabular}{|c|c|c|c|c|c|}
\hline & \multirow[t]{2}{*}{$\begin{array}{l}\text { Group I, nebivolol } \\
(n=30)\end{array}$} & \multirow[t]{2}{*}{$\begin{array}{l}\text { Control group } \\
(n=30)\end{array}$} & \multirow[t]{2}{*}{$\begin{array}{l}P \text {-value between } \\
\text { groups I and II }\end{array}$} & \multicolumn{2}{|c|}{$\begin{array}{l}\text { P-value between } \\
\text { initial and final }\end{array}$} \\
\hline & & & & Group I & Group II \\
\hline \multicolumn{6}{|c|}{ E' lateral $(\mathrm{cm} / \mathrm{s})$} \\
\hline Initial & $11.7 \pm 2.9$ & $11.7 \pm 3.0$ & 1 & 0.09 & $0.0 I^{*}$ \\
\hline Final & $10.5 \pm 2.6$ & $9.9 \pm 2.4$ & 0.35 & & \\
\hline \multicolumn{6}{|c|}{ E' septal $(\mathrm{cm} / \mathrm{s})$} \\
\hline Initial & $8.8 \pm 2.6$ & $8.7 \pm 2.4$ & 0.87 & 0.08 & $0.02 *$ \\
\hline Final & $7.7 \pm 2.3$ & $7.4 \pm 1.8$ & 0.57 & & \\
\hline \multicolumn{6}{|c|}{ E/E' (average) } \\
\hline Initial & $7.5 \pm 1.7$ & $7.5 \pm 1.5$ & I & 0.15 & $0.03 *$ \\
\hline Final & $8.1 \pm 1.6$ & $8.3 \pm 1.3$ & 0.59 & & \\
\hline \multicolumn{6}{|c|}{ TDIs lateral $(\mathrm{cm} / \mathrm{s})$} \\
\hline Initial & $9.9 \pm 2.1$ & $9.8 \pm 1.9$ & 0.84 & 0.68 & 0.20 \\
\hline Final & $10.1 \pm 1.7$ & $10.5 \pm 2.3$ & 0.44 & & \\
\hline \multicolumn{6}{|c|}{ TDls septal $(\mathrm{cm} / \mathrm{s})$} \\
\hline Initial & $8.8 \pm 1.6$ & $8.7 \pm 1.4$ & 0.79 & $0.4 \mathrm{I}$ & 0.11 \\
\hline Final & $9.1 \pm 1.2$ & $9.3 \pm 1.5$ & 0.57 & & \\
\hline \multicolumn{6}{|l|}{ LS (\%) } \\
\hline Initial & $-21.2 \pm 1.3$ & $-21.0 \pm 1.4$ & 0.56 & 0.07 & $0.04 *$ \\
\hline Final & $-20.5 \pm 1.7$ & $-20.2 \pm 1.6$ & 0.48 & & \\
\hline \multicolumn{6}{|l|}{ CS (\%) } \\
\hline Initial & $-20.4 \pm 0.5$ & $-20.2 \pm 0.4$ & 0.09 & 0.81 & 0.48 \\
\hline Final & $-20.3 \pm 2.3$ & $-20.0 \pm 1.5$ & 0.55 & & \\
\hline \multicolumn{6}{|l|}{ RS (\%) } \\
\hline Initial & $50.2 \pm 9.4$ & $50.4 \pm 9.2$ & 0.93 & 0.47 & $0.03 *$ \\
\hline Final & $48.3 \pm 10.5$ & $45.2 \pm 9.4$ & 0.23 & & \\
\hline \multicolumn{6}{|l|}{$\operatorname{LSR}(\mathrm{I} / \mathrm{s})$} \\
\hline Initial & $-1.1 \pm 0.34$ & $-1.1 \pm 0.14$ & 1 & 0.15 & $0.02 *$ \\
\hline Final & $-1.0 \pm 0.17$ & $-1.0 \pm 0.18$ & I & & \\
\hline \multicolumn{6}{|c|}{$\operatorname{CSR}(1 / s)$} \\
\hline Initial & $-1.6 \pm 0.3$ & $-1.6 \pm 0.4$ & I & 0.52 & 0.27 \\
\hline Final & $-1.5 \pm 0.8$ & $-1.5 \pm 0.3$ & I & & \\
\hline \multicolumn{6}{|l|}{$\operatorname{RSR}(\mathrm{I} / \mathrm{s})$} \\
\hline Initial & $2.5 \pm 0.6$ & $2.5 \pm 0.4$ & I & 0.23 & $0.02 *$ \\
\hline Final & $2.3 \pm 0.7$ & $2.2 \pm 0.6$ & 0.55 & & \\
\hline
\end{tabular}

Notes: Data are expressed as mean \pm SD. TDIs, tissue Doppler flow velocity in the ventricular myocardium. $* P<0.05$.

Abbreviations: E, left ventricular protodiastolic filling wave; E', early diastolic mitral annular velocity wave; LS, longitudinal strain; CS, circumferential strain; RS, radial strain; $L S R$, longitudinal strain rate; CSR, circumferential strain rate; RSR, radial strain rate.

induced by cytostatic treatment. Our study showed a reduction in longitudinal and radial ventricular strain parameters in the beta-adrenergic blocker unprotected group. The overall evaluation parameters of the LV systolic and diastolic function did not change over time in the two groups.

It is possible that at an early stage cardiotoxicity is segmental and the reduced function of the affected segments is compensated by the hyperfunction of the unaffected segments. Another possible explanation is that the strain imaging method has a higher sensitivity than LVEF, with some early incipient changes in ventricular function. Echocardiography is one of the most noninvasive methods most commonly used for early detection and monitoring of cardiomyopathy induced by cytostatic therapy. ${ }^{21}$ Early detection is important because changes are reversible under cardioprotective treatment. Standard echocardiographic measurements, such as LVEF and SF, reflect the overall dynamics of ventricular myocardial contraction and do not allow direct assessment of longitudinal, radial, and circumferential function. As many pathologies induce regional ventricular dysfunction, the echocardiographic evaluation of regional myocardial dysfunction is essential.

Recent studies have shown that strain and strain rate imaging have a higher sensitivity compared to standard echocardiographic parameters in the evaluation of cytostaticinduced myocardial contractility changes. In one study, the 


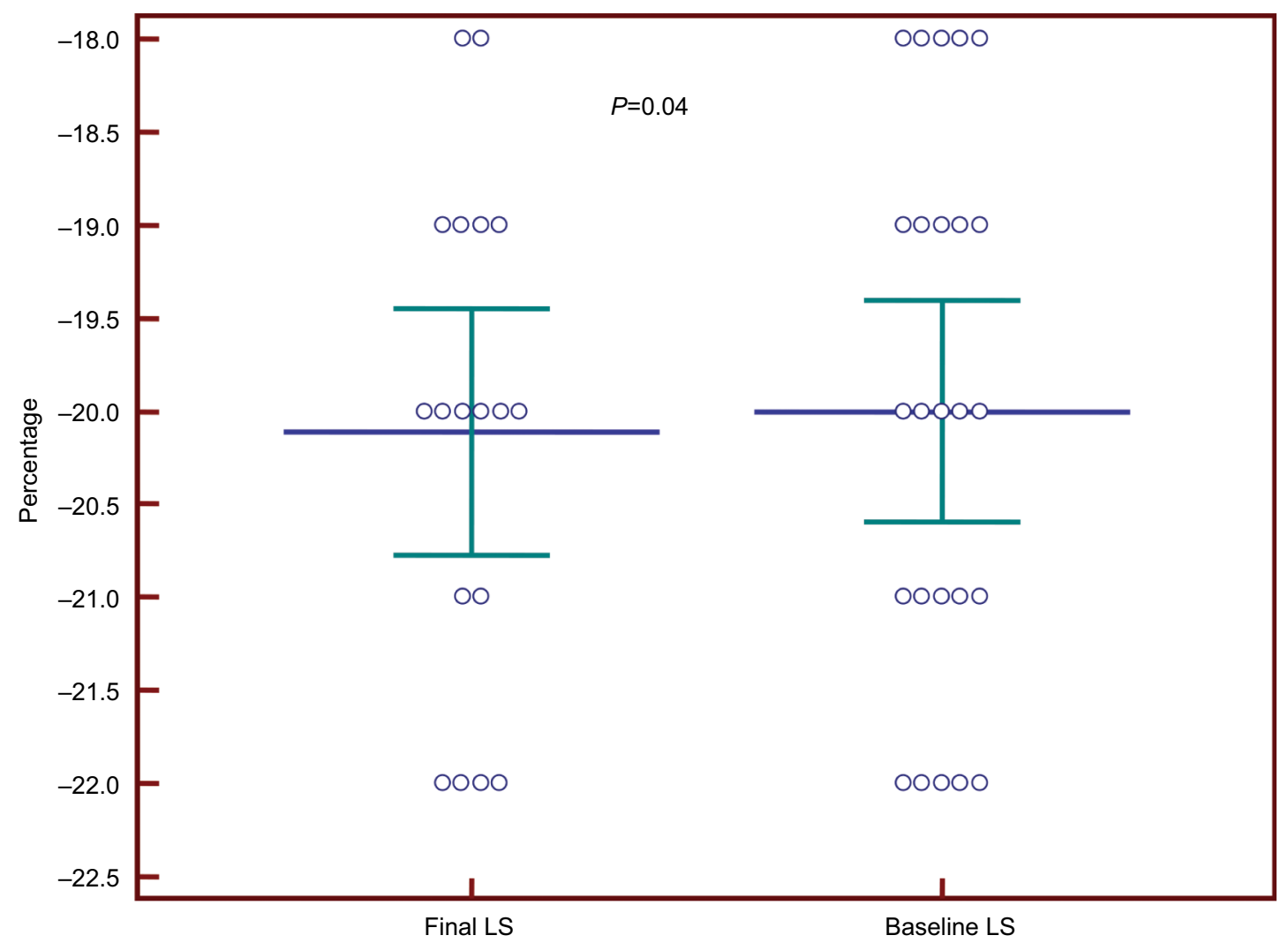

Figure 2 Reduction of the left ventricular LS in group II patients, after doxorubicin therapy. Abbreviation: LS, longitudinal strain.

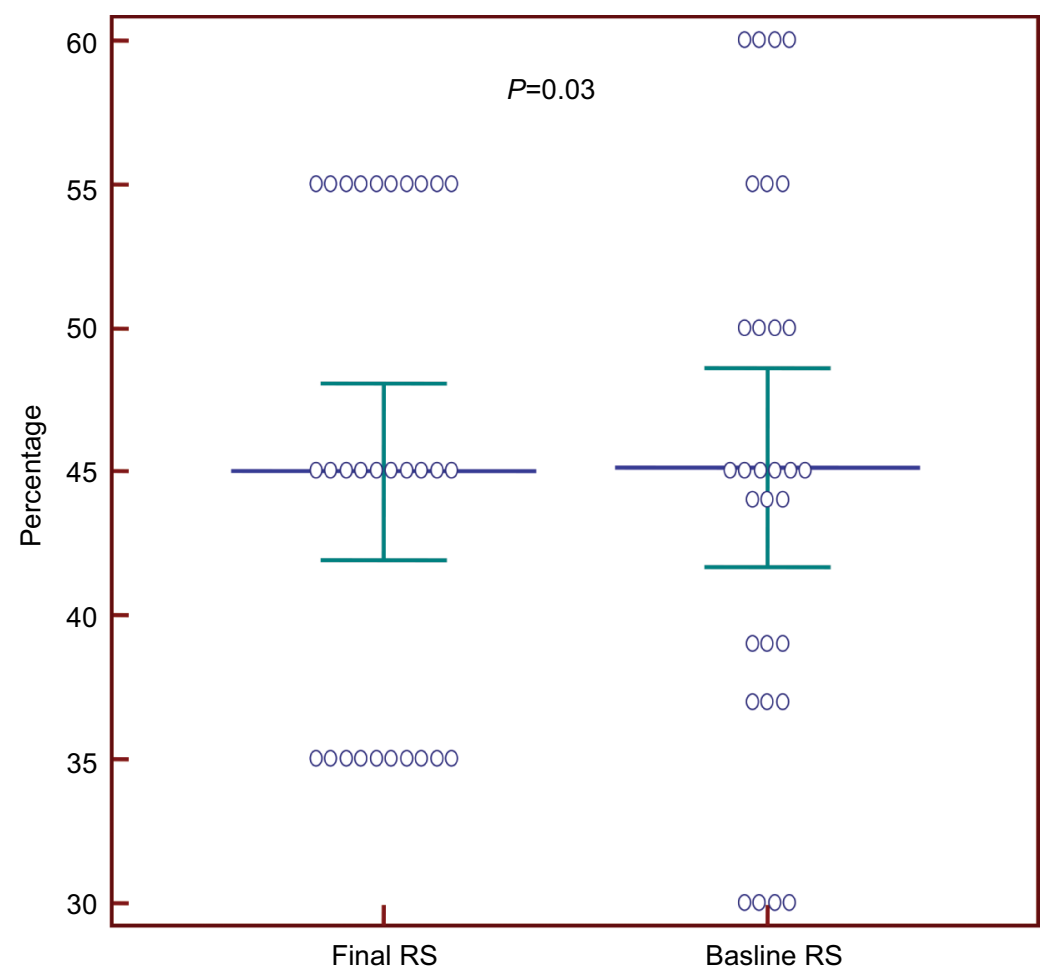

Figure 3 Reduction of the left ventricular RS in group II patients, after doxorubicin therapy. Abbreviation: RS, radial strain. 


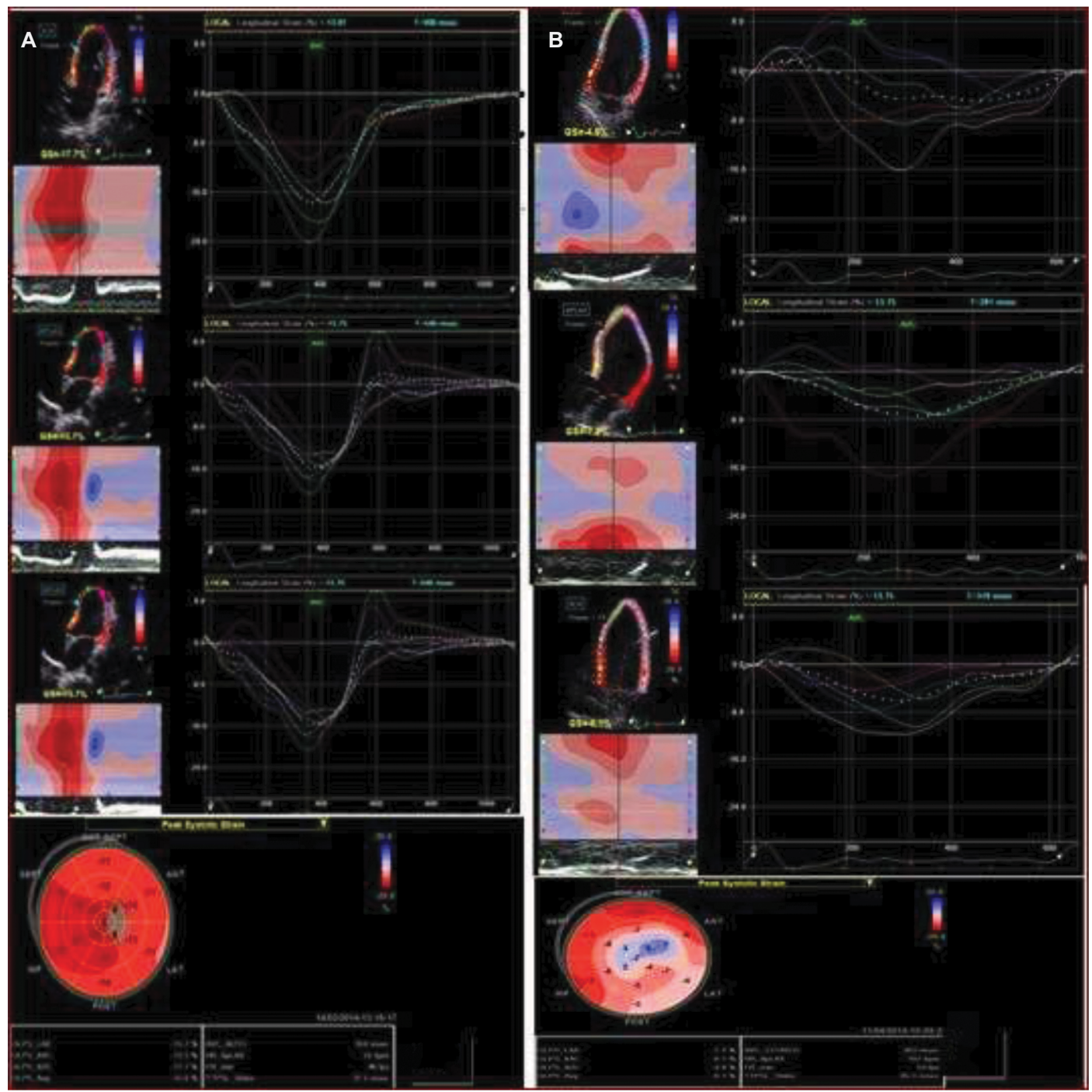

Figure 4 Speckle tracking imaging of the left ventricle longitudinal strain, before (A) and after (B) doxorubicin therapy, in a control group patient.

cytostatic treatment caused a $10 \%$ decrease in the longitudinal and radial strain of $\mathrm{LV}$ in over half of the patients, while no LVEF reduction of $>10 \%$ was found in any patient. ${ }^{22}$ Another study found that reduction of the longitudinal and radial strain after 3 months of cytostatic treatment may be a predictive factor of cardiotoxicity, as opposed to the reduction of LVEF after 3 months. ${ }^{23}$

Several hypotheses have been proposed to explain the cardiotoxicity of the cytostatics. Most refer to free oxygen radicals that induce apoptosis and myocardial lesions. ${ }^{24}$ Other incriminated mechanisms are lipid peroxidation, reduction of gene expression, inhibition of nucleic acid and protein synthesis, alteration of adrenergic function, and calcium homeostasis imbalance in mitochondria. ${ }^{25-27}$ The cardiotoxic effects of anthracycline are cumulative with the dose and irreversible. The risk of cardiotoxicity depends on factors such as age, association with other cytostatics, previous exposure to radiotherapy, pre-existing cardiopathy, and high cumulative doses. ${ }^{28}$ In addition, the incidence of anthracycline-induced cardiomyopathy depends to a large extent on the type of chemotherapy used, for example, epirubicin and liposomal doxorubicin being less cardiotoxic than adriamycin. ${ }^{15}$

Various methods have been attempted to reduce the cardiotoxicity of the cytostatics, such as modification of pharmacokinetics by liposomal encapsulation, modification of the chemical structure with the emergence of new drugs such as epirubicin, and iron chelation by pretreatment with dexrazoxane. All these methods have succeeded in reducing the cardiovascular complications of cytostatics, but they are not routinely used. ${ }^{29}$

Adrenergic beta-blockers have known cardioprotective effects recognized in systolic heart failure, but there are few 

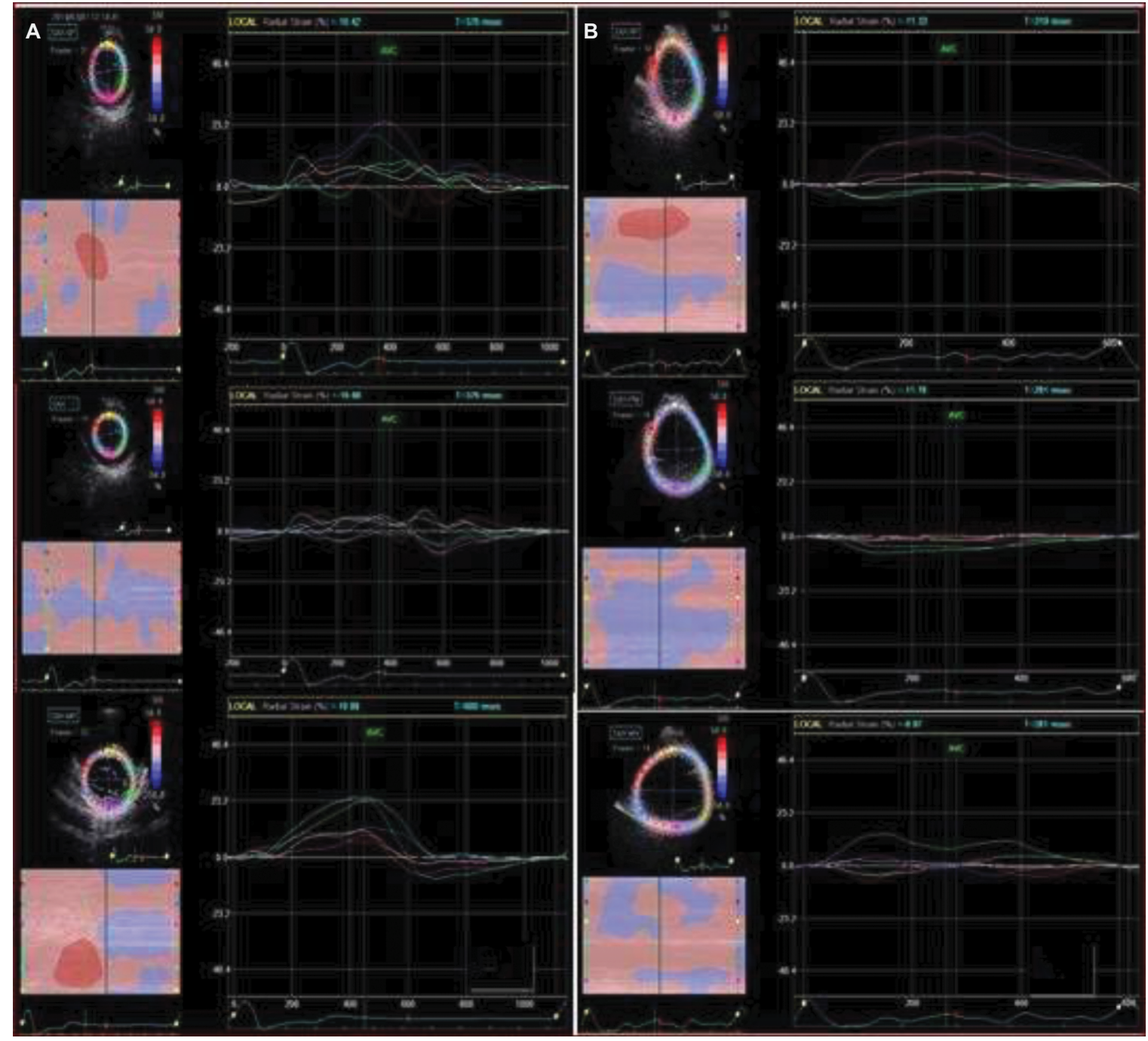

Figure 5 Speckle tracking imaging of the left ventricle radial strain, before (A) and after (B) doxorubicin therapy, in a control group patient.

studies of their cardioprotective effect in patients treated with cytostatics. This was partly due to the antioxidant effect of some beta-blockers. ${ }^{30,31}$ Other possible mechanisms would be to restore the activity of Ca-ATPase from the sarcoplasmic reticulum (SERCA2) of myocardiocytes ${ }^{32,33}$ and inhibit apoptosis. ${ }^{34}$ In addition, beta-blockers do not reduce the effectiveness of cytostatics. ${ }^{35}$ However, there are insufficient studies that support the routine use of adrenergic beta-blockers in cytostatic-induced cardiomyopathy.

In our study, the association of nebivolol to cytostatic medication prevented the appearance of subtle and early myocardial abnormalities that could be detected by TDI and STI in asymptomatic patients and normal LVEF. Our study data show that nebivolol has cardioprotective effects and prevents the cardiotoxicity of anthracyclines in the short term (6 months). These data cannot be extrapolated in the long term, and longer term studies are needed. Treatment with nebivolol did not affect LVEF and SF of the treated patients, nor the echocardiographic parameters of the diastolic ventricular function. Instead, it reduced the decrease in global ventricular strain, these data being in line with the results of other studies. ${ }^{15,18,35}$

Although the study has a number of limitations because of the small number of patients, the short follow-up and design, and not being double-blind randomized, it also has results that encourage treatment with nebivolol associated with anthracyclines.

\section{Conclusion}

The results of this study reveal the usefulness of new echocardiographic imaging methods, such as TDI and STI in the early recognition screening of cardiac dysfunction induced by cytostatic treatment.

Longitudinal and radial ventricular strain and strain parameters can be used in clinical practice to identify patients 


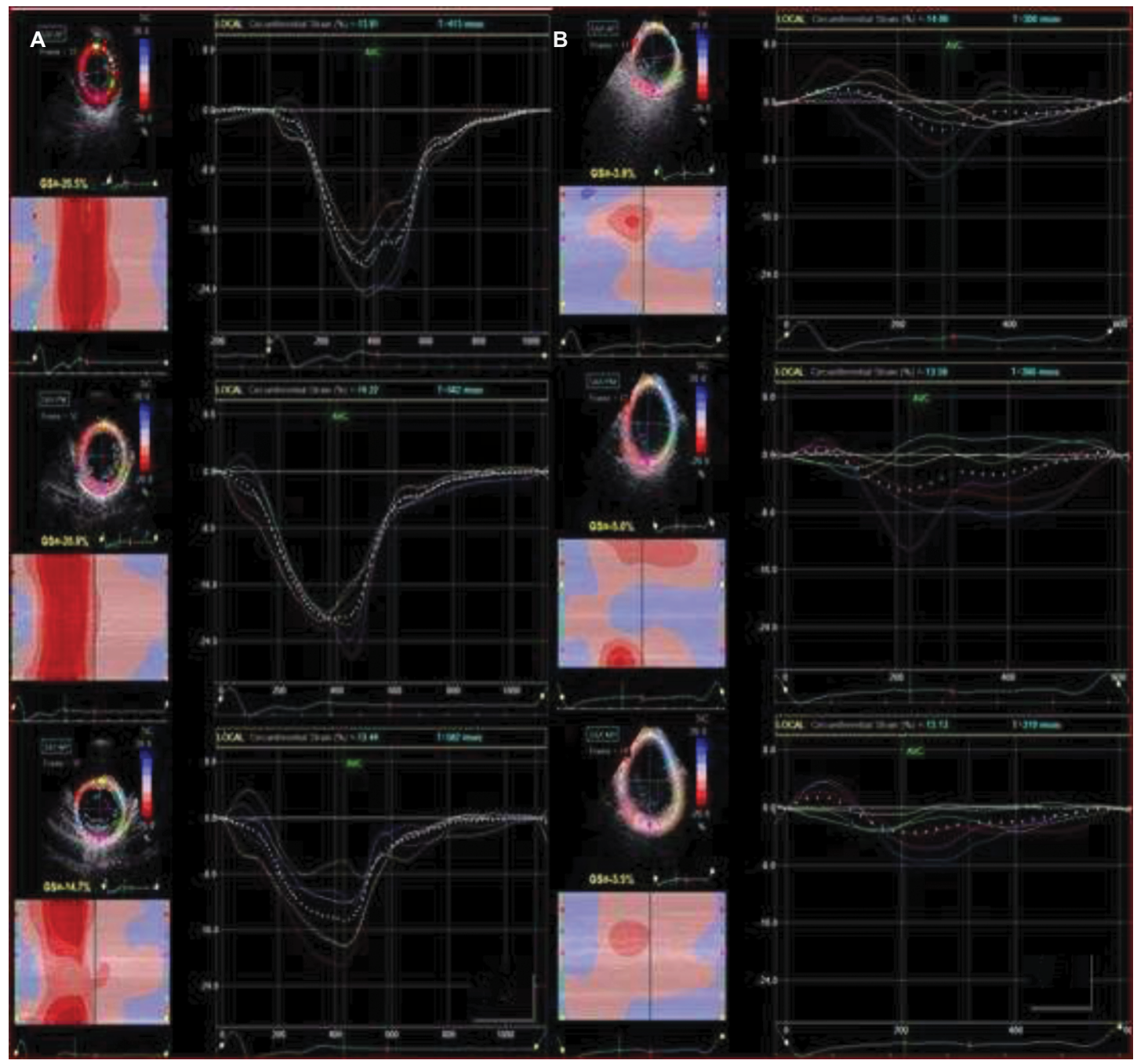

Figure 6 Speckle tracking imaging of the left ventricle circumferential strain, before (A) and after (B) doxorubicin therapy, in a control group patient.

at risk of developing irreversible cardiotoxicity under anthracycline therapy.

Adrenergic beta-blocking therapy associated with chemotherapy appears to have cardioprotective effects, but more patients and longer follow-up durations are needed to confirm these preliminary results.

\section{Author contributions}

All authors made substantial contributions to conception and design, acquisition of data, or analysis and interpretation of data; took part in drafting the article or revising it critically for important intellectual content; gave final approval of the version to be published; and agree to be accountable for all aspects of the work.

\section{Disclosure}

The authors report no conflicts of interest in this work.

\section{References}

1. WHO. Disease and injury country estimates. Geneva: World Health Organization; 2009. Available from: http://www.who.int/healthinfo/ global_burden_disease/estimates_country/en/.Accessed November 11, 2009.

2. Mornoş C, Petrescu L. Early detection of anthracycline-mediated cardiotoxicity: the value of considering both global longitudinal left ventricular strain and twist. Can J Physiol Pharmacol. 2013;91: 601-607.

3. Von Hoff DD, Layard MW, Basa P, et al. Risk factors for doxorubicininduced congestive heart failure. Ann Intern Med. 1979;91:710-717.

4. Swain SM, Whaley FS, Ewer MS. Congestive heart failure in patients treated with doxorubicin: a retrospective analysis of three trials. Cancer. 2003;97:2869-2879.

5. Singal PK, Li T, Kumar D, Danelisen I, Iliskovic N. Adriamycininduced heart failure: mechanism and modulation. Mol Cell Biochem. 2000;207:77-86.

6. Gyalai KI, Andor M, Tomescu MC, Bordejevic A, Marincu I. Speckle echocardiographic left atrial strain as predictor of atrial fibrillation recurrence in hypertensive patients. Healthmed. 2014;8:705-714.

7. Heimdal A, Stoylen A, Torp H, Skjaerpe T. Real-time strain rate imaging of the left ventricle by ultrasound. $J$ Am Soc Echocardiogr. 1998;11:1013-1019. 
8. Weiss R. Nebivolol: a novel beta-blocker with nitric oxide-induced vasodilatation. Vasc Health Risk Manag. 2006;2:303-308.

9. Veverka A, Salinas JL. Nebivolol in the treatment of chronic heart failure. Vasc Health Risk Manag. 2007;3:647-654.

10. Groarke JD, Nohria A. Anthracycline cardiotoxicity: a new paradigm for an old classic. Circulation. 2015;131:1946-1949.

11. Ewer MS, Lippman SM. Type II chemotherapy-related cardiac dysfunction: time to recognize a new entity. J Clin Oncol. 2005;23:2900-2902.

12. Volkova M, Russell R 3rd. Anthracycline cardiotoxicity: prevalence, pathogenesis, and treatment. Curr Cardiol Rev. 2011;7:214-220.

13. Shi Y, Moon M, Dawood S, McManus B, Liu PP. Mechanisms and management of doxorubicin cardiotoxicity. Herz. 2011;36:296-305.

14. Todorova VK, Makhoul I, Dhakal I, et al. Polymorphic variations associated with doxorubicin-induced cardiotoxicity in breast cancer patients. Oncol Res. 2017;25:1223-1229.

15. Hamo CE, Bloom MW, Cardinale C, et al. Cancer therapy-related cardiac dysfunction and heart failure. Part 2: prevention, treatment, guidelines, and future directions. Circ Heart Fail. 2016;9:e002843.

16. Dulin B, Abraham WT. Pharmacology of carvedilol. Am J Cardiol. 2004;93:3-6.

17. Nabati M, Janbabai G, Baghyari S, Esmaili K, Yazdani J. Cardioprotective effects of carvedilol in inhibiting doxorubicin-induced cardiotoxicity. J Cardiovasc Pharmacol. 2017;69:279-285.

18. Kaya MG, Ozkan M, Gunebakmaz O, et al. Protective effects of nebivolol against anthracycline-induced cardiomyopathy: a randomized control study. Int J Cardiol. 2013;167:2306-2310.

19. Choe JY, Combs AB, Folkers K. Potentiation of the toxicity of adriamycin by propranolol. Res Commun Chem Pathol Pharmacol. 1978;21:577-580.

20. Georgakopoulos P, Roussou P, Matsakas E, et al. Cardioprotective effect of metoprolol and enalapril in doxorubicin-treated lymphoma patients: a prospective, parallel-group, randomized, controlled study with 36-month follow-up. Am J Hematol. 2010;85:894-896.

21. Oreto L, Todaro MC, Umland MM, et al. Use of echocardiography to evaluate the cardiac effects of therapies used in cancer treatment: what do we know? J Am Soc Echocardiogr. 2012;25:1141-1152.

22. Stoodley PW, Richards DA, Hui R, et al. Two-dimensional myocardial strain imaging detects changes in left ventricular systolic function immediately after anthracycline chemotherapy. Eur J Echocardiogr. 2011;12:945-952.

23. Sawaya H, Sebag IA, Plana JC, et al. Early detection and prediction of cardiotoxicity in chemotherapy-treated patients. Am J Cardiol. 2011;107:1375-1380.

24. Palmeira CM, Serrano J, Kuehl DW, Wallace KB. Preferential oxidation of cardiac mitochondrial DNA following acute intoxication with doxorubicin. Biochim Biophys Acta. 1997;1321:101-106.
25. Mimnaugh EG, Trush MA, Bhatnagar M, Gram TE. Enhancement of reactive oxygen-dependent mitochondrial membrane lipid peroxidation by the anticancer drug adriamycin. Biochem Pharmacol. 1985;34:847-856.

26. Kang YJ, Chen Y, Yu A, Voss-McCowan M, Epstein PN. Overexpression of metallothionein in the heart of transgenic mice suppresses doxorubicin cardiotoxicity. J Clin Invest. 1997;100:1501-1506.

27. Liu J, Li J, Liu N, et al. In vitro studies of phospholipid-modified PAMAM-siMDR1 complexes for the reversal of multidrug resistance in human breast cancer cells. Int J Pharm. 2017;530:291-299.

28. Felker GM, Thompson RE, Hare JM, et al. Underlying causes and longterm survival in patients with initially unexplained cardiomyopathy. N Engl J Med. 2000;342:1077-1084.

29. Jones RL. Utility of dexrazoxane for the reduction of anthracyclineinduced cardiotoxicity. Expert Rev Cardiovasc Ther. 2008;6: 1311-1317.

30. Elitok A, Oz F, Cizgici AY, et al. Effect of carvedilol on silent anthracycline-induced cardiotoxicity assessed by strain imaging: a prospective randomized controlled study with 6-month follow-up. Cardiol $J$. 2014:21:509-515.

31. Dessy C, Sallez J, Ghishdal P, et al. Endothelial beta3-adrenoreceptors mediate nitric oxide-dependent vasorelaxation of coronary microvessels in response to third-generation beta-blocker nebivolol. Circulation 2005;112:1198-1205.

32. Matsui H, Morishima I, Numaguchi Y, Toki Y, Okumura K, Hayakawa T. Protective effects of carvedilol against doxorubicin-induced cardiomyopathy in rats. Life Sci. 1999;65:1265-1274.

33. Nohria A. B-Adrenergic blockade for anthracycline- and trastuzumabinduced cardiotoxicity: is prevention better than cure? Circ Heart Fail 2013;6:358-361.

34. Seicean S, Seicean A, Alan N, Plana JC, Budd GT, Marwick TH. Cardioprotective effect of $\beta$-adrenoreceptor blockade in patients with breast cancer undergoing chemotherapy: follow-up study of heart failure. Circ Heart Fail. 2013;6:420-426.

35. De Nigris F, Reienzo M, Schiano C, Fiorito C, Napoli C. Prominent cardioprotective effects of third generation beta blocker nebivolol against anthracycline-induced cardiotoxicity using the model of isolated perfused rat heart. Eur J Cancer. 2008;44:334-340.

36. Kalay N, Basar E, Ozdogru I, et al. Protective effects of carvedilol against anthracycline-induced cardiomyopathy. $\mathrm{J} \mathrm{Am} \mathrm{Coll} \mathrm{Cardiol}$. 2006;48:2258-2262
Cancer Management and Research

\section{Publish your work in this journal}

Cancer Management and Research is an international, peer-reviewed open access journal focusing on cancer research and the optimal use of preventative and integrated treatment interventions to achieve improved outcomes, enhanced survival and quality of life for the cancer patient The manuscript management system is completely online and includes
Dovepress

a very quick and fair peer-review system, which is all easy to use. Visit http://www.dovepress.com/testimonials.php to read real quotes from published authors. 